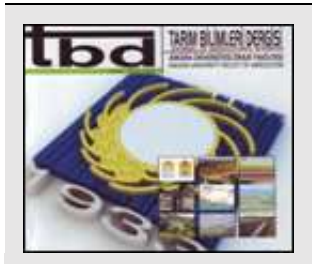

Tarım Bilimleri Dergisi Tar. Bil. Der.

Dergi web sayfasi: www.agri.ankara.edu.tr/dergi
Journal of Agricultural Sciences

Journal homepage:

www.agri.ankara.edu.tr/journal

\title{
Kernel Density Analysis of Parcel Size and Shapes Before and After Land Consolidation: A Case Study from Aşağısümenli Village in Malatya, Turkey
}

\author{
Firat ARSLAN ${ }^{\mathrm{a}}$, Hasan DEĞíRMENCí ${ }^{\mathrm{b}}$, Sinan KARTAL ${ }^{\mathrm{c}}$ \\ ${ }^{a}$ Alanya Alaaddin Keykubat University, Gazipaşa MRB Vocational School, Animal and Plant Production Department, Antalya, TURKEY

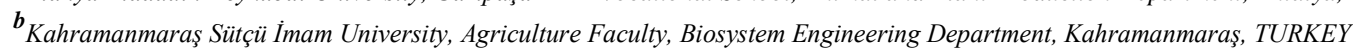

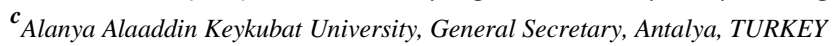

\author{
ARTICLE INFO \\ Research Article \\ Corresponding Author: Hasan DEĞİRMENCİ, E-mail: hdegirmenci46@gmail.com, Tel: +90 (344) 3002067 \\ Received: 01 March 2019, Received in Revised Form: 12 June 2019, Accepted: 19 June 2019
}

\section{AUTHORS ORCID ID:}

(Fırat ARSLAN: 0000-0002-7168-226X), (Hasan DEĞİRMENCİ: 0000-0002-6157-816X), (Sinan KARTAL: 0000-0002-9600-8052)

\begin{abstract}
Land consolidation (LC) projects are a set of applications that improve the economics of enterprises by assembling fragmented, dispersed, and irregular parcels. As the parcel densities coalesce around the village centre, the operation becomes easier, and fuel costs are reduced. Besides, the size of the parcel is one of the most important factors that increase the income of the enterprises, as well as the plant pattern, agricultural production form, soil quality, talents, labour force and technology features. The aim of the current study conducted within Aşağısümenli LC project in Malatya, Turkey, was to assess the density of small parcels around the village centre by using kernel density analysis as one of the geospatial analyses and to
\end{abstract}

investigate the spatial distribution of irregular parcels with shape index. To identify the smallest parcels spatial distribution, 50\%, 75\% and $90 \%$ bandwidths were determined. Before LC, the average parcel area within $50 \%, 75 \%$ and $90 \%$ bandwidth was $0.69,0.93$ and 1.07 ha; after LC was $0.89,1.45$ and 1.63 ha, respectively. The area averages of parcels between $50 \%$ and $75 \%$ bandwidths before LC were 1.79 between $75 \%$ and $90 \%$ bandwidths and 4.77 ha out of $90 \%$ bandwidth; after LC, 1.60, 2.47 and 3.13 ha, respectively. As a result, the small parcels after LC were more concentrated around the village centre than before LC. Moreover, it can be said that the density of the small rectangular shaped parcels around the centre of the village is a positive result in terms of reducing the operation cost.

\section{Introduction}

(C) Ankara Üniversitesi Ziraat Fakültesi

Optimum enterprise size is one of the most controversial topics in agriculture. In general terms, optimum enterprise size means agricultural enterprise size with the lowest cost (Gökçe \& Adanacioğlu 2002). Land consolidation (LC) applications help to decrease land fragmentation and hence increase enterprise size (Demirtaş \& Sar1 2003). Land fragmentation increases transportation distance which leads to more labour and time losses (Kakwagh et al 2011). The aim of LC is to eliminate these problems and try to achieve maximum benefit with minimum input (Boztoprak et al 2015). Also, while reallocation is being made, it is stated that the enterprises that would decrease land fragmentation should be encouraged and given priority in the location of the parcel which is close to the settlement and the area which is larger than the agreement.

Some significant effects of the LC works include the following: reduction of the distance from the enterprise centre to the village centre, making new and shorter roads, decreasing the winding roads with rectangle parcel shapes, decreasing the number of the parcels and increasing their sizes. However, in some cases (Değirmenci et al 2017) the number of parcels increased after LC due to many shares. This situation originates the social structure of the LC area. Generally, the 
number of parcels is increasing after LC projects in regions with a high number of family members. In addition to LC, expropriation (Boztoprak et al 2015) also affects the size of the parcel. In the study conducted in DSI (State Hydraulic

Works) 12. District region, the effects of expropriation on road construction and parcel size was investigated. Results showed that the size of the parcel decreased by $15.70 \%$. This situation leads to a decrease in per capita income (Kumbasaroğlu \& Dağdemir 2007; Looga et al 2018). Although the owners of the parcels appear single after the LC, they are divided because of some problems (Kirmikil et al 2017). Therefore, LC studies should be done in a multifaceted way, and the social-cultural characteristics of the region should be determined in a good idea. For LC projects to be successful, many factors should be taken into consideration, and monitoring studies should be done carefully.

Kernel density analysis is used in the following ways: to reduce traffic accidents on cross-roads (Xie \& Yan 2008); determination of movement and habitat use by fish in rivers (Alp et al 2018); assessment of accumulation of environmental pollution (Sirirwardane et al 2015); landscape change (Carmona et al 2010), road density as well as its impact on fragmentation (Cai et al 2013). Along with these studies, kernel density analysis can be used to determine the frequency of water table level, salinity content rate, plant density, etc. in agriculture. The studies on kernel density show that the importance of determining density using GIS allow researchers evaluate change.

Parcel size has one of the most significant effects on production (Değirmenci et al 2017). The complexity of shapes can be measured with various shape indices used commonly by researchers (Aslan et al 2007; Jiao et al 2012; Demetriou et al 2013; Kwinta \& Gniadek 2017). Unshaped parcels and parcel sizes should be taken into consideration together due to the connection they have on the effect on production. Parcel shape and size have long been a question of great interest in a wide range of fields. Previous published studies are limited and there is no considerable amounts of studies suggest an association between parcel size and shape. In land consolidation projects, parcel size and shape are of significant importance and surprisingly, the spatial distribution of parcel size considering shape have not been closely examined.

This study aims to analyse the distribution of small scale parcel sizes around the village centre and the spatial distribution of complexity of parcels before and after the LC project. In the province of Malatya, LC projects' data of Aşağısümenli Village was selected as the material, and kernel density analysis was used to determine the density of the parcels by using geographic information system programmes. The parcel sizes found before and after the LC were examined in the $50 \%, 75 \%$ and $90 \%$ band segments (core range contours) within the total parcel number.

\section{Material and Methods}

Aşağısümenli Village is located in the Arguvan district of Malatya province between $38^{\circ} 52^{\prime \prime} 12^{\prime}$ North parallels and $38^{\circ} 13^{\prime \prime} 38^{\prime}$ Eastern meridians. Figure 1 shows the LC project before and after including the location.

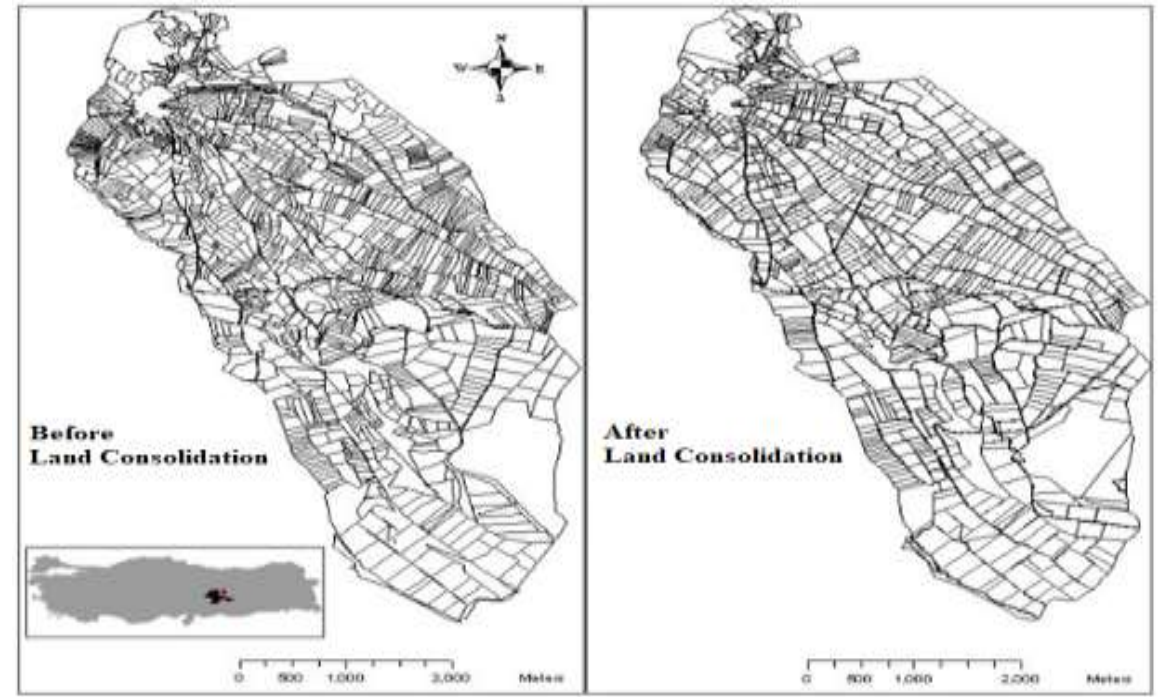

Figure 1- Aşağısümenli land consolidation project before and after land consolidation 
The region is under the influence of the continental climate. Winters are cold and snowy, and summers are usually hot and dry. The average annual rainfall is $374.9 \mathrm{~mm}$; the average temperature is $13.6{ }^{\circ} \mathrm{C}$ (Meteorological Service 2018). The number of parcels was 1357; the total area was 1963.94 ha (average 1.45 ha) before LC; after LC, the number of parcels decreased to 1082 , and the total area decreased to 1936.74 ha (mean 1.79 ha). Data were obtained from the company which designed the project.

The kernel density analysis calculates the density of features in a neighbourhood around those features. It can be estimated for both point and line features (ArcGIS 2018). In this context, Kernel density analysis of ArcGIS (ArcMap 10.5) was used to show districts where small parcels were located. Parcels which have polygon features were changed into point features due to kernel density analysis works with the point or line features. In this context, each point shows centroid of the parcel presents a polygon (Figure 2). ArcMap calculates the kernel density analysis following the algorithm:

1. Calculate the mean centre of the input points.

2. Calculate the distance from the (weighted) mean centre for all points.

3. Calculate the (weighted) median of these distances, Dm.

4. Calculate the (weighted) Standard Distance, $S D$.

5. Apply the following formula (Equation 1) to calculate the bandwidth:

$$
S R=0.9 \times \min \left(S D, \sqrt{\frac{1}{\ln (2)}} \times D m\right) \times n^{-22}
$$

Where; $S R$ is search radius, $S D$ is the standard distance, $D m$ is the median distance and $n$ is the number of points if no population field is used, or if a population field is supplied, $n$ is the sum of the population field values (ESRI 2019).

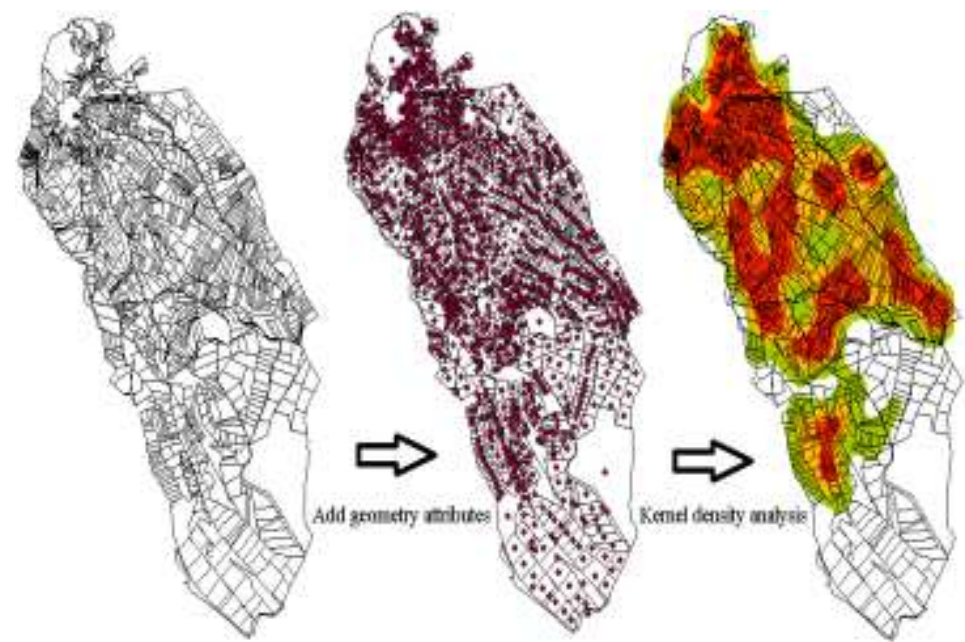

Figure 2- A methodology of kernel density analysis of parcels

Buffer analysis was used to show parcel location change clearly. We consider buffer analysis is tools which may make readers see the change of it with core range contour around village centre. Core range contours were divided into 3 groups which are $50 \%, \% 75$ and $90 \%$ which are considered representative range. These classifications indicate the smallest parcels. For example the core range contours $50 \%$ represent the smallest parcels according to the sort by size. These ranges can be considered with different percentages of core range contours according to researcher aims as well.

Fractal dimension is an index of many shape indices that measure shape complexity and is used in many studies (Aslan et al 2007; Demetriou et al 2013; Bayram \& Değirmenci 2018). We chose the index due to the precision level measuring agricultural parcels' complexity (Bayram \& Değirmenci 2018). It is calculated by using the following Equation (2); 


$$
F D=\frac{2 \ln \left(P_{i}\right)}{\ln \left(A_{i}\right)}
$$

Where; $F D$ is the fractal dimension, $P_{i}$ is the perimeter of $i$ parcel, $A_{i}$ is the area of $i$ parcel. This ratio can take values from 1 to 2 , and 1 shows optimum shaped parcels.

\section{Results and Discussion}

Figure 3 shows the core ranges of contours and distance from the village centre within 2000 metres buffers before and after LC. The size of parcels within the core range contours shows the smallest parcels before or after LC. $50 \%$ of all parcels which have the smallest size within the project are shown in red core contour, $75 \%$ in yellow core contour and $90 \%$ in green core contour.

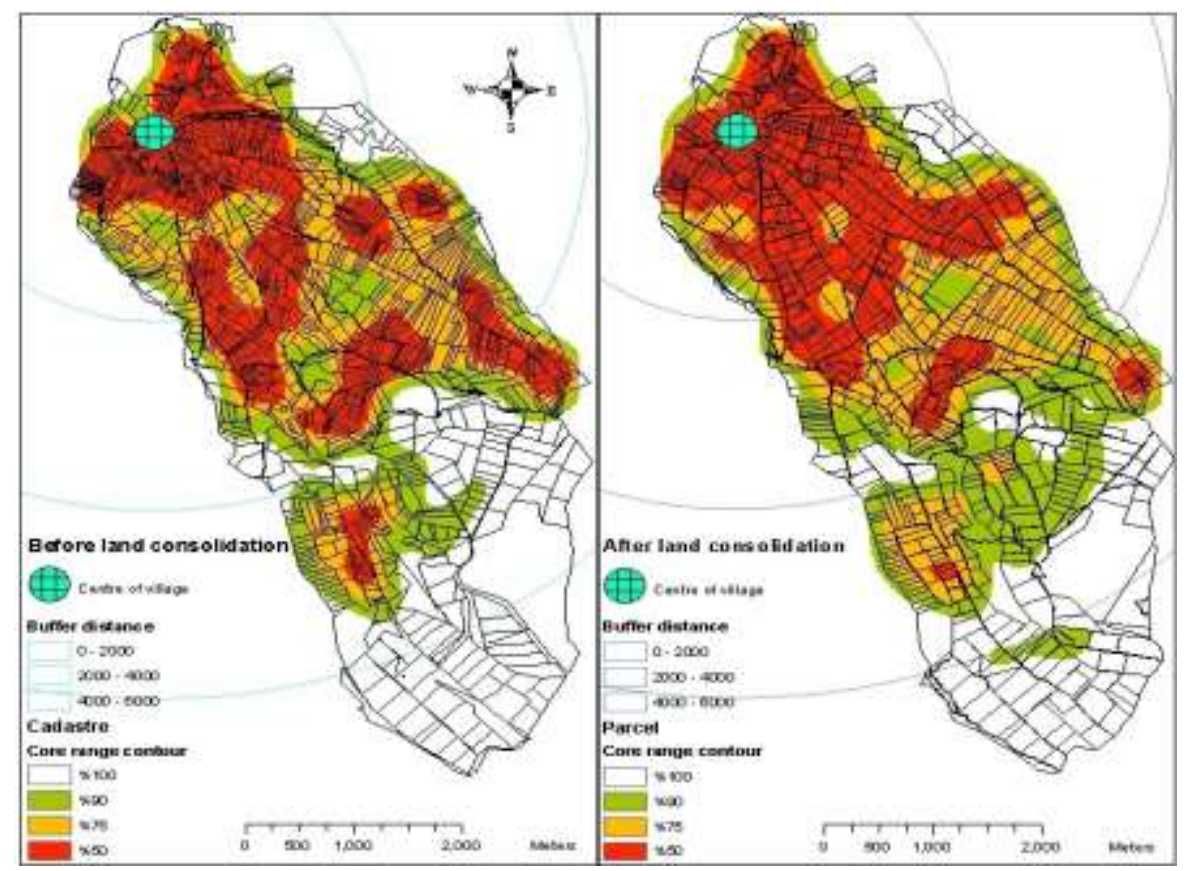

Figure 3- Kernel density analysis according to parcel size before and after land consolidation project

Table 1 illustrates total, average area and the number of parcels as well as average fractal dimension before and after LC within core range contours. Red represents $50 \%$ of the number of parcels present within core range contour $50 \%$ and an average parcel size of 0.7 ha for 687 parcels which covered 469.7 ha before LC. Yellow represents $75 \%$ of the number of parcels within the $75 \%$ core range contour which includes 937.9 ha with 1017 number of parcels; the average area was 0.9 ha before LC. Green represents $90 \%$ of the number of parcels which cover 1310.1 ha with 1221 parcels, and the average area was 1.1 ha before LC. After LC, total area, average area and number of parcels for $50 \%$ core range contour, were 729.6 ha, 0.9 ha and 541 respectively; for $75 \%$ core range contour were 1168.1 ha, 1.5 ha and 811 respectively; for $90 \%$ core range contour were 1582.8 ha, 1.6 ha and 973 , respectively. The average fractal dimension value (1.38) after LC increased from the optimum value (1.37) which was not considerable change. In the present study, fractal dimension values increased with increase in parcel area. It was determined that the parcels where the density of small size parcels was previously located (red contour) had more regular shapes before and after LC and vice versa.

Correlation analysis showed a significant negative relation between area and fractal dimension $(\mathrm{P}<0.01)$ before LC. Results of the present study showed parcel area decreases of 1 metre, fractal dimension decrease of 0.24 and closing to 1 which is the optimum value. The Pearson correlation of area and fractal dimension in this study was- 0.301 , and the Pvalue is smaller than 0.001 ; in other words, there was a significant negative correlation between these parameters after LC. 
Table 1- Descriptive statistics of kernel density before and after land consolidation

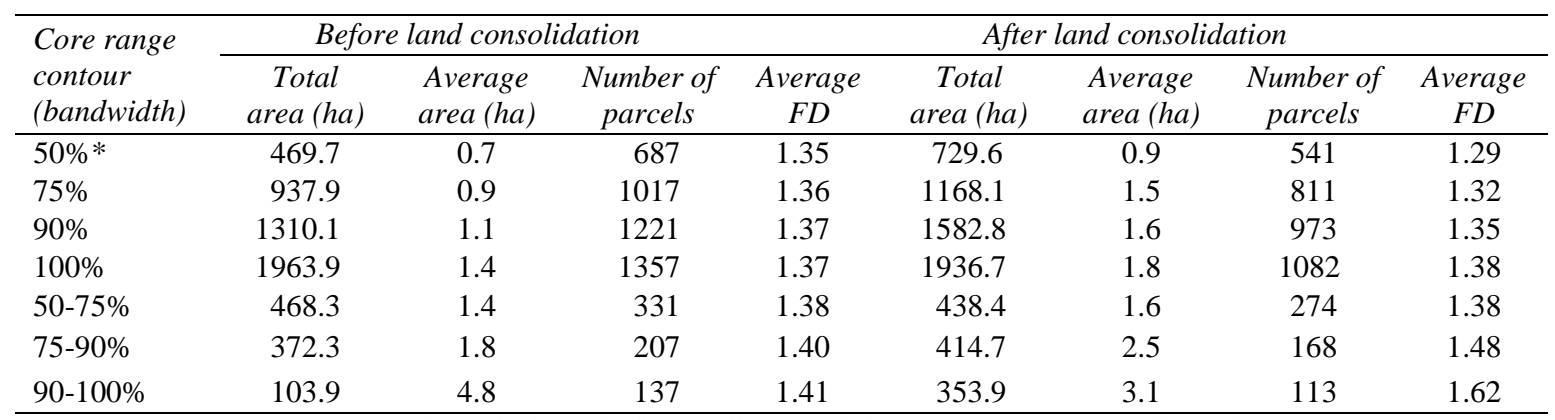

*Core range contours: $50 \%, 75 \%$ and $90 \%$ indicate the first smallest parcels by sort, $100 \%$ represent all parcels

Figure 3 shows the small size parcels located around the village centre after LC. Farmers who had small size parcels consumed less fuel and earned more comparing due to the shorter road before LC. Farm size was not a matter of this study; however, the size of parcels and the size of the farm are closely related (Assunçao \& Ghatak 2003; Barrett et al 2010). In this context, parcel size was interpreted as a factor decreasing agricultural production.

In this case, it can be said that enterprises with small parcels could benefit. Lu et al (2018) mentioned that the economic examination owned by all enterprises have to be taken into consideration. In their study, when the Simpson index one of the fragmentation indices decreases by 1 unit, the average cost decreases by $39 \%$. Their results indicated that enterprises are negatively affected by fragmentation. Lu et al (2018) also mentioned that 1 unit increase in parcel size ensures an $8 \%$ decrease in the average cost of an enterprise. In this study, the parcel size, which was 0.7 ha before LC, increased to 0.9 ha when the smallest parcel was examined for $50 \%$ core range contour. For $75 \%$ core range contour, the parcel size increased from 0.9 to 1.5 ha and within $90 \%$ core range contour, parcel size increased from 1.1 ha to 1.5 ha.

Moreover, the number of parcels decreased from 1357 to 1082 . In this case, it was concluded that the fragmentation decreased and had an effect on the average parcel size. According to the previous study by Lu et al (2018), it can be said an increase of 0.4 ha leads to a $3.2 \%$ decrease in the average cost of the farmers in the village.

Small parcels may be shown with simple classification, but the density of small size parcels cannot be seen clearly in areas where they mostly gather (Figure 4). Kernel density analysis shows a good performance in clearly understanding the density of small size parcels and how they changed after LC contrary to the classification. Shortly, the figure is a strong evidence of kernel density analysis to show the density of parcels.
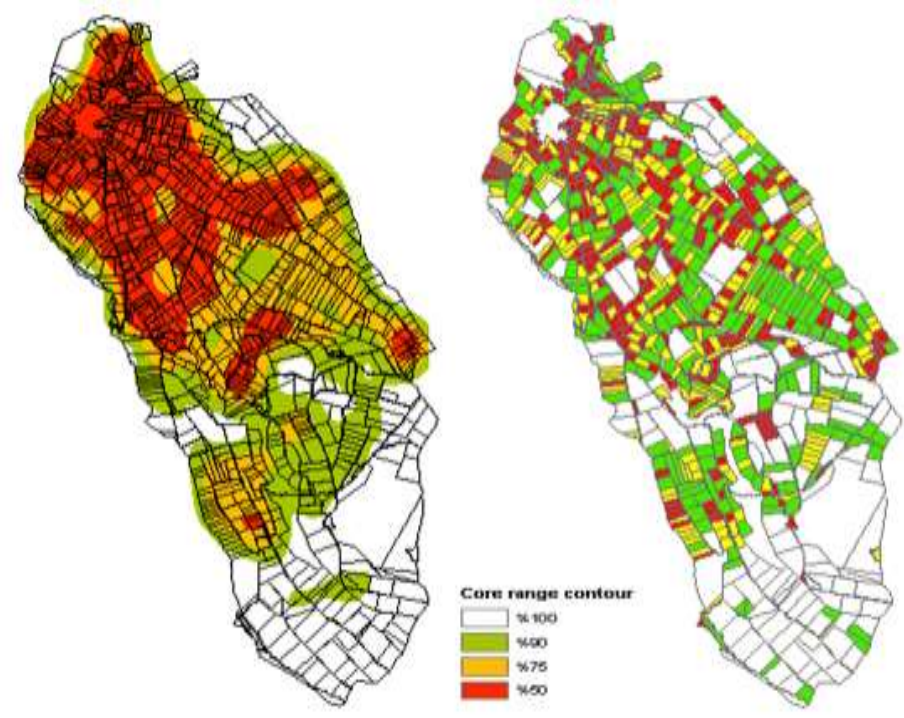

Figure 4- General view of kernel density and classification analysis 


\section{Conclusions}

If small size parcels are reallocated around the village centre, it may help farmers with low-income. Sufficient agricultural land can be arranged according to the distance to the village centre. Engineers who are in charge of LC projects can take into consideration the distances of these small size parcels when they hold interviews with farmers. Farmers should be encouraged to farm together. These precautions may prevent migration to cities, thanks to increased production. Kernel density could be used to determine the frequency of parcels according to size. It is found that parcels have a high density within first bandwidth with a less complicated shape according to spatial distribution. After LC projects, it may be essential to reallocate small size parcels nearer to the village centre and to reshape the big size parcels to increase production. In this study, land fragmentation was not taken into consideration. As a conclusion, kernel density analysis can help managers to see change parcels location with size by sort in land consolidation projects. The analysis may assist engineers to do better projects with regard to spatial distribution of parcels before and after land consolidation. Future studies on this topic may be carried out on land fragmentation and conduct comparisons with sufficient agricultural land size and shape of enterprises.

\section{References}

Alp A, Akyüz A, Özcan M \& Yerli S V (2018). Assessment of movements and habitat use of Salmo opimus in Firnız stream, river Ceyhan of Turkey using radio telemetry techniques. Environmental Biology of Fishes 101(11): 1613-1624

ArcGIS (2018). Kernel Density. Retrieved in December, 15, 2018 from http://pro.arcgis.com/en/pro-app/tool-reference/spatialanalyst/how-kernel-density-works.htm (Last access date: 15.10.2018)

Aslan T, Gündoğdu K \& Arıcı İ (2007). Some metric indices for the assessment of land consolidation projects. Pakistan Journal of Biological Sciences 10(9): 1390-1397

Assunçao J J \& Ghatak M (2003). Can unobserved heterogeneity in farmer ability explain the inverse relationship between farm size and productivity. Economics Letters 80(2): 189-194

Barrett C B, Bellemare M F \& Hou J Y (2010). Reconsidering conventional explanations of the inverse productivity-size relationship. World Development 38(1): 88-97

Bayram R \& Değirmenci H (2018). Analysis of parcel shapes in land consolidation projects: A Case Study of Niğde Misli Plain 2. Part. KSU Journal of Agricultural and Nature 21(4): 500-510

Boztoprak T, Demir O, Coruhlu Y E \& Nişancı R (2015). Investigating the land consolidations' effects on agricultural enterprises. Selcuk University Journal of Engineering, Science and Technology 3(3): 1-9

Cai X, Wu Z \& Cheng J (2013). Using kernel density estimation to assess the spatial pattern of road density and its impact on landscape fragmentation. International Journal of Geographical Information Science 27(2): 222-230

Carmona A, Nahuelhual L, Echeverría C \& Báez A (2010). Linking farming systems to landscape change: an empirical and spatially explicit study in southern Chile. Agriculture, Ecosystems \& Environment 139(1): 40-50

Değirmenci H, Arslan F, Tonçer R \& Yoğun E (2017). Evaluation of land fragmentation parcel shapes before land consolidation Project: A Case Study of Tirhan Village in Niğde Misli Plain. Journal of Agricultural Faculty of Gaziosmanpasa University 34(3): 182-189

Demetriou D, See L \& Stillwell J (2013). A parcel shape index for use in land consolidation planning. Transactions in GIS 17(6): 861882

Demirtaş E I \& Sarı M (2003). Arazi Toplulaştırması (Land consolidation). Derim 20(1): 48-58

ESRI (2019). How kernel density Works. Retrieved in February 27, 2019, from https://pro.arcgis.com/en/pro-app/toolreference/spatial-analyst/how-kernel-density-works.htm

Gökçe O \& Adanacıoğlu H (2002). An Investigation on determining of optimum farm size in agriculture. In: Processing of the Turkey 5. Agricultural Economics Congress, 12-18 September, Erzurum, pp. 97-101 
Jiao L, Liu Y \& Li H (2012). Characterizing land-use classes in remote sensing imagery by shape metrics. ISPRS Journal of Photogrammetry and Remote Sensing 72: 46-55

Kakwagh V V, Aderonmu J A \& Ikwuba A (2011). Land Fragmentation and Agricultural Development in Tivland of Benue State, Nigeria. Current Research Journal of Social Sciences 3(2): 54-58

Kirmikil M, Aslan S, Gundogdu K S \& Arici I (2017). The hidden fragmentation after land consolidation in Turkey. Fresenius Environmental Bulletin 26(10): 5882-5890

Kumbasaroğlu H \& Dağdemir V (2007). Economic analysis of farms with respect to land fragmentation in central district of Erzurum province. Atatürk University Journal of the Agricultural Faculty 38(1): 49-58

Kwinta A \& Gniadek J (2017). The description of parcel geometry and its application in terms of land consolidation planning. Computers and Electronics in Agriculture 136: 117-124

Looga J, Jürgenson E, Sikk K, Matveev E \& Maasikamäe S (2018). Land fragmentation and other determinants of agricultural farm productivity: The case of Estonia. Land Use Policy 79: 285-292

Lu H, Xie H, He Y, Wu Z \& Zhang X (2018). Assessing the impacts of land fragmentation and plot size on yields and costs: A translog production model and cost function approach. Agricultural Systems 161: 81-88

Meteorological Service (2018). Malatya Long Years Climate Data. Ankara, Turkey

Sirirwardane M S, Samanmali M A D \& Rathnayake R N (2015). Cloud based GIS approach for monitoring environmental pollution in the coastal zone of Kalutara, Sri Lanka. Journal of Tropical Forestry and Environment 5(1): 9-18

Xie Z \& Yan J (2008). Kernel density estimation of traffic accidents in a network space. Computers, Environment and Urban Systems 32(5): 396-406 